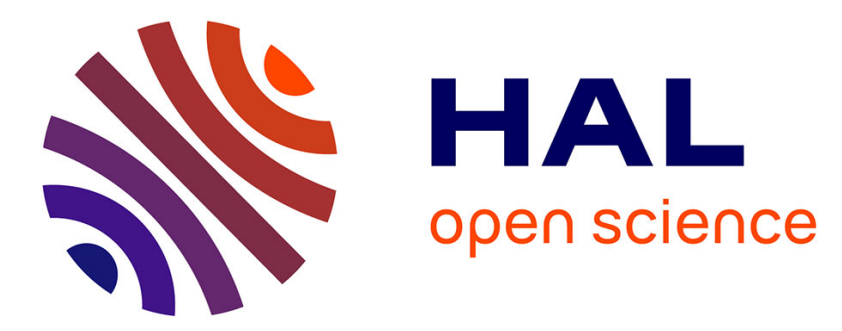

\title{
CDK11p58 kinase activity is required to protect sister chromatid cohesion at centromeres in mitosis
}

\author{
Tarik Rakkaa, Christophe Escudé, Régis Giet, Laura Magnaghi-Jaulin, \\ Christian Jaulin
}

\section{- To cite this version:}

Tarik Rakkaa, Christophe Escudé, Régis Giet, Laura Magnaghi-Jaulin, Christian Jaulin. CDK11p58 kinase activity is required to protect sister chromatid cohesion at centromeres in mitosis. Chromosome Research, 2014, 22 (3), pp.267-276. 10.1007/s10577-013-9400-x . hal-01078683

\section{HAL Id: hal-01078683 https://hal.science/hal-01078683}

Submitted on 31 Oct 2014

HAL is a multi-disciplinary open access archive for the deposit and dissemination of scientific research documents, whether they are published or not. The documents may come from teaching and research institutions in France or abroad, or from public or private research centers.
L'archive ouverte pluridisciplinaire HAL, est destinée au dépôt et à la diffusion de documents scientifiques de niveau recherche, publiés ou non, émanant des établissements d'enseignement et de recherche français ou étrangers, des laboratoires publics ou privés. 


\section{$\mathrm{CDK11}^{\mathrm{p} 58}$ kinase activity is required to protect sister chromatid cohesion at centromeres in mitosis}

Rakkaa Tarik ${ }^{1}$, Escudé Christophe ${ }^{2}$, Giet Régis ${ }^{1}$, Magnaghi-Jaulin Laura ${ }^{1}$ and Jaulin Christian*1

IInstitut de Génétique et Développement de Rennes, Equipe Epigénétique et Cancer, UMR 6290 CNRS, Université Rennes 1, 35043, Rennes cedex, France.

${ }^{2}$ UMR7196 MNHN-CNRS, Muséum National d'Histoire Naturelle, 75231 Paris Cedex 05, France

Correspondence to:

*Christian Jaulin: +33 2232343 29; christian.jaulin@univ-rennes1.fr

Running title: CDK11p58 and sister chromatid cohesion 


\begin{abstract}
:
The cyclin-dependent kinase $\mathrm{CDK} 11^{\mathrm{p} 58}$ is specifically expressed at $\mathrm{G} 2 / \mathrm{M}$ phase. CDK11 $1^{\mathrm{p} 58}$ depletion leads to different cell cycle defects such as mitotic arrest, failure in centriole duplication and centrosome maturation and premature sister chromatid separation. We report that, upon CDK11 depletion, loss of sister chromatid cohesion occurs during mitosis but not during G2 phase. CDK1 $1^{\mathrm{p} 58}$ depletion prevents Bub1 and Shugoshin 1 recruitment but has no effect on the dimethylation of histone $\mathrm{H} 3$ lysine 4 at centromeres. We also report that a construct expressing a kinase dead version of CDK1 $11^{\text {p58 }}$ fails to prevent CDK11 depletioninduced sister chromatid separation, showing that $\mathrm{CDK} 11^{\mathrm{p} 58}$ kinase activity is required for protection of sister chromatid cohesion at centromeres during mitosis. Thus, CDK1 $1^{\text {p58 }}$ kinase activity appears to be involved in early events in the establishment of the centromere protection machinery.
\end{abstract}




\section{Keywords:}

Sister chromatid cohesion, CDK11, Centromere, Mitosis, Mammalian cells.

\section{Abbreviations}

CDK1 $11^{\mathrm{p} 58}$

Cyclin-dependent kinase 11, p58 isoform

CDK11 $11^{\mathrm{p} 10}$

Cyclin-dependent kinase 11, p110 isoform

CREST

Calcinosis, Raynaud's phenomenon, Esophageal dysmotility,

Sclerodactyly Telangiectasia

FISH

Fluorescence in situ hybridization

H2AT120P

Phosphorylated H2AT120

H3K4diM

Dimethylated H3K4

H3S10P

Phosphorylated H3S10

IRES

Internal ribosomal entry site

PSCS Premature sister chromatids separation

SAC Spindle assembly checkpoint

siRNA Small interference RNA 


\section{Introduction:}

At every cellular division, chromosomes must be equally segregated into each daughter cell. In order to ensure accurate segregation, sister chromatid cohesion must be maintained from its establishment during DNA replication until the metaphase-anaphase transition. Loss of sister chromatid cohesion before anaphase onset results in segregation defects that lead to aneuploidy, with significant potential deleterious consequences such as infertility, birth defects, tumorigenesis and cell death .

Sister chromatid cohesion is mediated by cohesin, a ring-shaped protein complex, loaded on chromatin in G1, stabilized upon replication fork progression and thought to embrace and hold together the two sister chromatids. In vertebrates, two distinct events account for cohesin removal during mitosis. First, in prophase, phosphorylation of the cohesin SA2 subunit by Plk1 and phosphorylation of the pro-cohesion factor Sororin by CDK1 and Aurora B occur . Sororin phosphorylation leads to its displacement from cohesin and its replacement by the anti-cohesion factor WAPL . During this step, called "prophase pathway", sister chromatid cohesion is lost on chromosome arms but remains protected at centromeres. At the metaphase-anaphase transition, when all kinetochores are attached to spindle microtubules, the satisfaction of the kinetochore attachment checkpoint (also called "SAC", for "Spindle Assembly Checkpoint" ) leads to the release of an active form of the separase, a proteolytic enzyme that cleaves the Scc1 subunit of the remaining centromeric cohesin. Protection of cohesion at centromeres during mitosis early stages is mediated by Shugoshin 1 (Sgo1) . Sgo1 is recruited at inner centromeres during early mitosis following Bub1-mediated phosphorylation of histone $\mathrm{H} 2 \mathrm{~A}$ at threonine 120 . SGO collaborate with protein phosphatase 
2A (PP2A) which is thought to participate to protection of cohesion at centromeres by counteracting SA2 and Sororin phosphorylation. We had previously reported that depletion of histone deacetylase HDAC3 (histone deacetylase) leads to loss of protection of sister chromatid cohesion at centromeres in a separase-independent manner. HDAC3 depletion causes displacement of Sgol from centromeres and is correlated with forced acetylation and loss of dimethylation on Lys4 of histone $\mathrm{H} 3$ at centromeres .

CDK11 (previously known as PITSLRE) is a member of the $\mathrm{cdc}^{\mathrm{p} 34}$ related protein kinase family and is encoded by CDK11A and CDK11B genes. The CDK11 mRNA is translated into two major CDK11 proteins: a full-length $110 \mathrm{kDa}$ isoform, CDK11 $1^{\mathrm{p} 110}$, and a shorter 58 $\mathrm{kDa}$ protein, $\mathrm{CDK} 11^{\mathrm{p} 58}$, corresponding to the C-terminal moiety of CDK $11^{\mathrm{p} 110} \cdot \mathrm{CDK} 11^{\mathrm{p} 110}$ is expressed during all stages of the cell cycle and is involved in transcription regulation and mRNA splicing . During G2 and M phases, upon activation of an internal ribosome entry site (IRES) present in the CDK11 mRNA, CDK11 ${ }^{\mathrm{p} 58}$ is expressed and it is required for centrosome maturation and centriole duplication . CDK11 depletion by RNAi leads to premature sister chromatid separation (PSCS), a phenotype that can be rescued by the expression of a construct encoding $\mathrm{CDK} 11^{\mathrm{p} 58}$. The authors report that, upon CDK11 depletion, Bub1 is absent from centromeres and Sgo1 is still present but its localization relative to the CREST signal is altered. This result is puzzling since Bub1 is required to phosphorylate H2AT120 at centromeres which, in turn, recruits Sgo1 . Loss of sister chromatid cohesion may result from different events at different stages of the "cohesin cycle". For example, failure to recruit cohesin on chromatin in G1, lack of cohesin stabilization following replication fork progression in $\mathrm{S}$ phase or defects in the protection of cohesion at centromeres in mitosis can all lead to premature sister chromatid separation. We report that CDK11 $1^{\mathrm{p} 58}$ is required for both Bub1 and Sgo1 localization at centromeres, but not for 
centromere cohesion in $\mathrm{G} 2$, making $\mathrm{CDK} 11^{\mathrm{p} 58}$ part of the centromere protection machinery. We also show that the CDK $11^{\mathrm{p} 58}$ kinase activity is essential for this function.

\section{Materials and methods:}

\section{Cell culture and RNAi:}

HeLa-S3cells were cultured in Dulbecco's Modified Eagle's Medium (DMEM) supplemented with $10 \%$ fetal bovine serum (FBS), $0.03 \%$ L-glutamine, $100 \mathrm{U} / \mathrm{mL}$ penicillin, and 100 $\mu \mathrm{g} / \mathrm{mL}$ streptomycin. G418 (1 $\mathrm{mg} / \mathrm{ml})$ was added to the culture medium of cell lines expressing an EGFP-CDK11 $1^{\mathrm{p} 58}$ construct. The cells were transfected with luciferase siRNA (as a negative control) or a CDK11 siRNA (5'AGCGGCUGAAGAUGGAGAA-3') that targets the endogenous CDK11 mRNA but not the GFP-CDK11 mRNA using Hiperfect (Qiagen) as a transfection reagent. Immunofluorescence was performed 72 hours after transfection.

\section{Plasmid constructs and establishment of stable cell lines:}

The pEGFP- CDK11 ${ }^{\mathrm{p} 58}$ wild type construct has been described before . This construct has been designed to be resistant to the siRNA used in this study. To obtain the pEGFPCDK $11^{\mathrm{p} 58} \mathrm{KD}$ construct, pEGFP- CDK $11^{\mathrm{p} 58}$ was amplified and mutated in its kinase domain (D224N) using the QuickChange II site-directed mutagenesis kit (Agilent Technologies) following manufacturer instructions with the following oligonucleotides: (5`TACTCCCGCGCCAGCCCAAAGTTACCCACCTTGAGGATGCC $3{ }^{\prime}$ and 5'GGCATCCTCAAGGTGGGTAACTTTGGGCTGGCGCGGGAGTA 3')

HeLa-S3 cells were transfected with the relevant plasmids using the transfection reagent Lipofectamine (Invitrogen). Stably transfected cells were selected with $1 \mathrm{mg} / \mathrm{ml} \mathrm{G418}$ and 
cloned by limiting dilution. Individual clones were expanded in selective media before being tested for EGFP-CDK1 $11^{\mathrm{p} 58}$ expression by Western blotting.

\section{Immunofluorescence:}

Cells were cytocentrifugated and fixed for $20 \mathrm{~min}$ in $3 \%$ paraformaldehyde in PBS (pH 7). Cells were then permeabilized in 1X PBS containing $0.1 \%$ Triton X100 and $100 \mathrm{mM}$ Glycerol. Following saturation of non-specific sites by incubation for $60 \mathrm{~min}$ in 5\% FBS, cells were incubated overnight at $4{ }^{\circ} \mathrm{C}$ with the primary antibody and for $45 \mathrm{~min}$ at room temperature with the secondary antibody. DNA was stained with DAPI $(0,1 \mu \mathrm{g} / \mathrm{ml})$. Slides were mounted in ProLong Gold (Invitrogen) and observed by epifluorescence microscopy (Zeiss Axio Imager M2). Fluorescence quantification at centromeres was performed using Image-J software.

\section{Antibodies:}

Antibodies used in this work: mouse anti-Bub1, rabbit anti-phospho-H2A (T120) [Active Motif \#39391, \#39392]; rabbit anti-dimethyl-H3 (K4) [Cell signaling \#9725], rabbit antiphospho-H3 (T3) [Abcam \#ab17352], rabbit anti-actin [Sigma \#A5060], mouse anti H3S10P [Millipore \#05-806]. Affinity-purified rabbit anti-Sgo1 was a gift from Pr Yoshinori Watanabe and rabbit anti-CDK11 antibody was previously described . Human CREST serum was a gift from Dr Isabelle Bahon-Riedinger. Alexa Fluor coupled secondary antibodies from Invitrogen and horseradish peroxydase coupled secondary antibodies from (Jackson ImmunoResearch) were used for detection.

\section{Fluorescence In Situ Hybridization:}

HeLa cells were transfected with CDK11, Scc1 or Luciferase siRNA. 48 hours after transfection, FISH experiment was performed using the procedure described by Schmitz et al. 
with minor modifications. The synthetic probe used is specific for chromosome 11 centromere (5'-A488/AgGgTtTcAgAgCtGcTc, where uppercase letters are for DNA nucleotides and lowercase letters are for "locked nucleic acid" (LNA) nucleotides) and leads to three independent signals in the aneuploid HeLa-S3 cell line.

\section{Results}

\section{Loss of sister chromatid cohesion following CDK11 depletion is not a consequence of premature mitosis exit:}

HeLa-S3 cells were transfected with a siRNA that targets the CDK11 mRNA 3'end and that was successfully used to deplete CDK11 in a previous study. . Immunoblotting with a polyclonal CDK11 antibody 72 hours after CDK11 siRNA transfection shows efficient depletion of both CDK11 isoforms (Figure 1A). HeLa cells depleted of CDK11 displayed increased mitotic index (8.26\% vs. 3.3\% in control cells) (Figure 1B), and increased premature sister chromatid separation $(51.75 \%$ vs. $4.43 \%)$ (Figure 1C), confirming the findings reported by $\mathrm{Hu}$ et al. .

To ensure that sister chromatid separation was not a consequence of a precocious mitotic exit followed by an accumulation of cells in anaphase, chromosome spreads from CDK11depleted cells were labeled with an anti-phospho H3S10 antibody. H3S10 is phosphorylated during mitosis and this phosphorylation is rapidly lost upon anaphase onset. As shown on figure 1D, CDK11-depleted cells chromosomes displaying sister chromatid separation display strong H3S10P labeling, indicating that these mitotic cells have not progressed in the cell cycle beyond the metaphase to anaphase transition. 


\section{Loss of sister chromatid cohesion upon CDK11 depletion is restricted to mitosis:}

Previous studies have reported that the lack of the short isoform (p58) of CDK11 is responsible for the cohesion defect observed in CDK11 depletion experiments . Since CDK $11^{\mathrm{p} 58}$ is expressed during G2 and $\mathrm{M}$ stages of the cell cycle, it can be involved in the establishment of cohesion in S/G2 phase, in its maintenance during G2 phase, or in the protection of cohesion at centromeres against the prophase pathway phosphorylation waves during mitotic early stages. In order to assess whether sister chromatid cohesion was established and maintained upstream of mitosis, we examined the inter-centromere distance of sister chromatids pairs in G2 phase nuclei. Hela-S3 cells were transfected with luc siRNA, CDK11 siRNA or Scc1 siRNA and inter-centromere distance was measured in G2 cells 48 hours after transfection. Since Scc1 is a component of the cohesin complex, its depletion prevents establishment of sister chromatid cohesion in interphase and, thus, Scc1- depleted cells are used as a positive control for loss of cohesion in G2. Chromosome 11 centromeres were labeled by FISH using a synthetic probe developed by us. Results displayed on Figure 2 show that the inter-centromere distances in CDK11 depleted G2 cells are undistinguishable from that of the mock-transfected control cells $(0.86 \mu \mathrm{m}$ vs. $0.78 \mu \mathrm{m}$ respectively). In contrast, this distance was increased to $1.34 \mu \mathrm{m}$ in Scc1 depleted cells. These data show that cohesion at centromere is not lost in G2 cells upon CDK11 depletion.

\section{CDK11 is required for Bub1 and Sgo1 localization at centromeres:}

Since CDK11 depleted cells do not display sister chromatid separation in G2, we assessed the presence of factors involved in the protection of cohesion at centromeres during mitosis. We focused on the main known centromere cohesion "guardian", Shugoshin, and on the elements involved in its deposition at centromeres. Human Sgol starts to accumulate at inner 
centromeres during prophase and is retained until the onset of anaphase . Its recruitment is mediated by the mitotic checkpoint protein Bub1. Bub1 phosphorylates human histone $\mathrm{H} 2 \mathrm{~A}$ at centromeres on threonine 120 (H2AT120) and this phosphorylation is essential for Sgo1 recruitment . As the Bub1/H2A-T120/Sgo1 pathway is established in early mitosis to protect cohesion at centromeres and CDK11 is involved in cohesion beyond the G2 phase, we assessed whether CDK11 depletion could affect the Bub1/H2A-T120/Sgo1 pathway. CDK11depleted cells were labeled with anti-Bub1, anti-Sgo1 and anti-H2AT120P antibodies. Human CREST autoimmune serum was used as a centromere marker and centromere signal intensities for the different labelings were quantified. CDK11 depletion induced an almost complete loss of Bub1 (Fig. 3A), H2AT120P (Fig. 3B) and Sgo1 (Fig. 3C) signals from centromeres in mitotic cells displaying PSCS, whereas the CREST signal was not affected. We had previously reported that HDAC3 depletion resulted in loss of $\mathrm{H} 3 \mathrm{~K} 4$ dimethylation at centromeres, lack of Sgol recruitment and premature sister chromatid separation . We therefore assessed whether CDK11 depletion could affect $\mathrm{H} 3 \mathrm{~K} 4$ dimethylation at centromeres. As shown on Figure 3D, separated sister chromatids in CDK11 depleted cells do not show any detectable H3K4 dimethylation defect at centromeres.

\section{CDK11 $^{\text {p58 }}$ kinase activity is required for protection of sister chromatid cohesion at centromeres:}

We then asked whether CDK1 $11^{\mathrm{p} 58}$ kinase activity was involved in the protection of sister chromatid cohesion. We generated two HeLa-S3 cell lines stably expressing either a wild-type GFP tagged-CDK11 ${ }^{\mathrm{p} 58}$ or a D224N "kinase dead" version. Five silent mutations were introduced into the siRNA target sequence in order to make both GFP-tagged transgenes mRNAs resistant to the siRNA used in this study. As shown on Figure 4A, CDK11 RNA 
interference in these cell lines results in the depletion of both endogenous CDK11 isoforms but not of the $90 \mathrm{kD}$ GFP-tagged protein expressed from the transgene. Figure 4B shows the results of rescue experiments using wild-type and "kinase dead" versions of GFP-CDK $11^{\mathrm{p} 58}$. Expression of the GFP-CDK11 ${ }^{\mathrm{p} 58}$ wild-type construct in cells depleted for the endogenous CDK11 was able to rescue both the increased mitotic index (Figure 4B) and the cohesion defect phenotypes $(3.5 \%$ PSCS in mock-transfected cells vs. $2.8 \%$ in CDK11 siRNA transfected cells, Figure 4C). In contrast, phenotype rescue was not observed in the cell line expressing the GFP-CDK11 ${ }^{\mathrm{p} 58}$ kinase dead mutant after CDK11 depletion (4\% PSCS in mock-transfected cells vs. $28.2 \%$ in CDK11 RNAi cells, Figure 4C). Similar results were obtained for the proportion of cells in mitosis following CDK11 depletion (Figure 4B).

\section{Discussion:}

Maintenance of sister chromatid cohesion until anaphase onset is a critical process required to prevent segregation defects which would lead to aneuploidy and, eventually, cell death or cancer. Premature sister chromatid separation may result from different causes, the most obvious of which being unscheduled mitosis exit. We assessed whether CDK11-depleted cells displaying PSCS had exit mitosis and found that separated sister chromatids were positive for the widely used mitotic marker phospho-H3S10 (Figure 1), indicating that these cells had not crossed the metaphase to anaphase border. Thus, CDK11 depletion results in a sister chromatid cohesion defect that may originate from a defect in any step of the cohesin cycle, such as cohesin loading onto chromatin in G1, sister chromatid cohesion establishment and maintenance in $\mathrm{S}$ and $\mathrm{G} 2$, or protection of cohesion during mitosis. The depletion of a cohesin subunit such as Scc1 leads to lack of cohesin loading and cohesion establishment and results in loose association of sister chromatids in G2 cells . However, CDK11-depleted cells 
do not show this "loose association" phenotype in G2 (Figure 2), indicating that loss of cohesion in these cells occurs beyond the G2/M transition.

Vertebrates have evolved a mechanism, known as the "prophase pathway", by which cohesin is actively taken off chromosome arms during early mitosis stages, cohesion being protected at centromeres . The benefits of such a mechanism are not clear but it is thought that removing most of the cohesin from chromatin may allow to build up a stock of intact soluble cohesin that will be readily usable during the early steps of the next cell cycle . Individualizing condensed chromosome arms in prophase may also be a way to prevent chromatin entanglement between sister chromatids during chromosome segregation. Protection of cohesion at centromeres is mediated by the evolutionary conserved protein Shugoshin, whose association to phosphatase PP2A is thought to counteract PLK1-mediated phosphorylation of cohesin during the prophase pathway. Shugoshin is loaded on centromeres in late G2 phase and is secured at centromeres by binding histone H2A upon its phosphorylation on threonine 120 by the checkpoint kinase Bub1 . We have previously reported that depletion of the deacetylase HDAC3 results in forced acetylation and loss of dimethylation of histone $\mathrm{H} 3$ lysine 4 at centromeres. The loss of $\mathrm{H} 3 \mathrm{~K} 4$ dimethylation correlates with sister chromatid separation and displacement of Sgo1 from centromeres . We report that, upon $\mathrm{CDK} 11$ depletion, $\mathrm{H} 3 \mathrm{~K} 4$ dimethylation at centromeres is unaffected, while centromere signals corresponding to Bub1, H2AT120 and Sgo1 become barely detectable compared to a control (Figure 3). These findings indicate that CDK11 acts downstream of dimethylated H3K4 and upstream of the Bub1/H2AT120/Sgo1 axis to protect sister chromatid cohesion. In agreement with our data, a previous study on the involvement of CDK11 in sister chromatid cohesion reported that, upon CDK11 depletion, Bub1 interaction with centromeres was destabilized. However, the authors found that Sgo1, although mislocalized, was not absent from centromeres . This represents a clear discrepancy: in our study, CDK11 depletion 
leads to a $90 \%$ decrease of Sgol signal at centromeres. A possible explanation is that $\mathrm{Hu}$ et al. used a shRNA expression vector and observed cells 48 hours post-transfection while we used a siRNA and looked at cells after 72 hours. The amount of time required to express the shRNA and to process it would reduce the period of time during which the cell progress into the cell cycle in the absence of CDK11. Thus, upon CDK11 depletion, Sgo1 would be first destabilized from centromeres but still detectable and, with time, it would detach from chromatin. We reported a similar phenomenon for Haspin-mediated phosphorylation of H3T3 at centromeres when Shugoshin is not present: upon Sgol depletion, H3T3P is first delocalized from centromeres to chromosome arms and, 96 hours post-transfection, its signal is no longer detectable .

Phosphorylation activity of centromeric kinases is not always required to their function at centromeres. For example, Bub1 kinase activity is essential for H2AT120 phosphorylation and subsequent Sgo1 recruitment, but is not required for SAC signaling in mammalian cells . We show that CDK $11^{\mathrm{p} 58}$ kinase activity is required for its role in the protection of sister chromatid cohesion (Figure 4). Since centromere protection seems to rely on cross-talks between histone modifications (H3K4diMe, H2AT120P) and soluble factors recruited at centromeres, it was tempting to speculate that histones can be phosphorylated by CDK $11^{\mathrm{p} 58}$. Thus, we immunoprecipitated GFP-CDK $11^{\mathrm{p} 58}$ from the corresponding cell line and used it in a kinase assay with bulk histones as a substrate. We did not detect any histone phosphorylation (not shown), suggesting that the relevant $\mathrm{CDK} 11^{\mathrm{p} 58}$ substrate must be a non-histone protein. Thus, identification and characterization of this substrate represents a major goal in the understanding of the establishment of protection of sister chromatid cohesion at centromeres during mitosis. 


\section{Acknowledgments:}

We are grateful to Yoshinori Watanabe (University of Tokyo, Japan), Isabelle BahonRiedinger (Rennes University Hospital, France) for the gift of reagents and to Erwan Watrin (IGDR, CNRS, Rennes, France) for stimulating helpful discussions. T.R. is supported by a Ligue Contre le Cancer/Région Bretagne fellowship, C.J. is an investigator at the Institut National de la Santé et de la Recherche Médicale (INSERM). Funding was from the French National Research Agency (ANR, project "EpiCentr"), the Région Bretagne (SAD grant), the Cancéropôle Grand-Ouest, the Ligue Contre le Cancer (Comité Grand Ouest) and the Fondation ARC pour la Recherche sur le Cancer.

The authors (T.R, C.E., R.G., L.M.-J. and C.J.) declare that they have no conflict of interest.

This article does not contain any studies with human or animal subjects performed by any of the authors 


\section{Figures legends:}

Figure 1. CDK11 depletion induces sister chromatid separation in mitotic cells.

(A). Immunoblot showing $\mathrm{CDK} 11^{\mathrm{p} 110}$ and $\mathrm{CDK} 11^{\mathrm{p} 58}$ protein levels depleted by siRNA transfection. Cells were analyzed 72 hours post- transfection. The membrane was probed with an anti-CDK11 antibody that recognizes both CDK11 isoforms. Actin was used as a loading control. Quantification of mitotic indexes (B) and PSCS (C) of HeLa cells depleted or not for CDK11. More than 100 mitotic cells per transfection were observed to quantify PSCS and the mitotic index was determined on at least 1000 cells. (D). Immunofluorescence microscopy on chromosome spreads obtained by cytocentrifugation of HeLa cells transfected as in (A), stained with CREST serum (red), anti-H3S10P (green) and DAPI. Scale bar is $10 \mu \mathrm{m}$.

Figure 2. CDK11 depletion does not induce sister chromatid separation in G2.

(A). FISH on chromosome spreads in G2 HeLa cells. Cells were transfected with si-Luc, siCDK11 or si-Scc1 and observed after $48 \mathrm{~h}$. The FISH probe (green) is specific for the chromosome 11 centromere. DNA was counterstained with DAPI (blue). Scale bar is $10 \mu \mathrm{m}$. (B). Measurement of the inter-centromere distance in HeLa cells transfected as in (A). Measurements were done on 100-200 sister chromatid pairs per transfection.

Figure 3. CDK11 is required for centromere targeting of factors involved in the Bub1/Sgo1 pathway. Immunofluorescence microscopy analysis on chromosome spreads obtained by 
cytocentrifugation of mitotic HeLa cells 72 hours after transfection with the indicated siRNA. Cells were labeled for Bub1 (A), H2AT120 (B) and Sgo1 (C) (green). Cells were co-labeled with CREST serum (red) and DAPI (blue). Scale bar is $10 \mu \mathrm{m} .$. Quantification of Bub1, H2AT120 and Sgo1 signals at centromeres is shown on left panels.

(D). Immunofluorescence microscopy showing isolated chromosomes (left panel) of HeLa cell transfected 72 hours by si-Luc, si-CDK11 or si-HDAC3 and stained for H3K4diM (green), CREST (red) and DAPI (blue). White arrows point to the H3K4diM signal at centromeres. Scale bar is $1 \mu \mathrm{m}$.

Figure 4. $\mathrm{CDK} 11^{\mathrm{p} 58}$ kinase activity is required for protection of sister chromatid cohesion.

(A). Immunoblot analysis showing CDK11 $1^{\mathrm{p} 110}$, GFP-CDK $11^{\mathrm{p} 58}, \mathrm{CDK} 11^{\mathrm{p} 58}$ and actin protein levels in HeLa-S3, GFP-CDK11p58 wild type and GFP-CDK11p58 kinase dead cell lines transfected with si-Luc or si-CDK11 and collected 72 hours after transfection and probed with anti-CDK11 antibody or an anti-actin antibody as a loading control. GFP-tagged constructs are resistant to the CDK11 siRNA. Quantification of mitotic index (B) and PSCS (C) of HeLa-S3, GFP-CDK11 ${ }^{\text {p58 }}$ wild type and GFP-CDK11 ${ }^{\text {p58 }}$ kinase dead cell lines transfected as in (A). At least 800 cells were counted for mitotic index and PSCS. 


\section{References:}

ALEXANDRU, G., UHLMANN, F., MECHTLER, K., POUPART, M. A. \& NASMYTH, K. 2001. Phosphorylation of the cohesin subunit Scc1 by Polo/Cdc5 kinase regulates sister chromatid separation in yeast. Cell, 105, 459-72.

CORNELIS, S., BRUYNOOGHE, Y., DENECKER, G., VAN HUFFEL, S., TINTON, S. \& BEYAERT, R. 2000. Identification and characterization of a novel cell cycle-regulated internal ribosome entry site. Mol Cell, 5, 597-605.

EOT-HOULLIER, G., FULCRAND, G., WATANABE, Y., MAGNAGHI-JAULIN, L. \& JAULIN, C. 2008. Histone deacetylase 3 is required for centromeric H3K4 deacetylation and sister chromatid cohesion. Genes Dev, 22, 2639-44.

FRANCK, N., MONTEMBAULT, E., ROME, P., PASCAL, A., CREMET, J. Y. \& GIET, R. 2011. $\mathrm{CDK} 11(\mathrm{p} 58)$ is required for centriole duplication and Plk4 recruitment to mitotic centrosomes. PLoS One, 6, e14600.

GIMENEZ-ABIAN, J. F., SUMARA, I., HIROTA, T., HAUF, S., GERLICH, D., DE LA TORRE, C., ELLENBERG, J. \& PETERS, J. M. 2004. Regulation of sister chromatid cohesion between chromosome arms. Curr Biol, 14, 1187-93.

GURURAJAN, R., GRENET, J., LAHTI, J. M. \& KIDD, V. J. 1998. Isolation and characterization of two novel metalloproteinase genes linked to the Cdc2L locus on human chromosome 1p36.3. Genomics, 52, 101-6.

HAUF, S., ROITINGER, E., KOCH, B., DITTRICH, C. M., MECHTLER, K. \& PETERS, J. M. 2005. Dissociation of cohesin from chromosome arms and loss of arm cohesion during early mitosis depends on phosphorylation of SA2. PLoS Biol, 3, e69.

HAUF, S., WAIZENEGGER, I. C. \& PETERS, J. M. 2001. Cohesin cleavage by separase required for anaphase and cytokinesis in human cells. Science, 293, 1320-3.

HENDZEL, M. J., WEI, Y., MANCINI, M. A., VAN HOOSER, A., RANALLI, T., BRINKLEY, B. R., BAZETT-JONES, D. P. \& ALLIS, C. D. 1997. Mitosis-specific phosphorylation of histone $\mathrm{H} 3$ initiates primarily within pericentromeric heterochromatin during $\mathrm{G} 2$ and spreads in an ordered fashion coincident with mitotic chromosome condensation. Chromosoma, 106, $348-60$. 
HOLLAND, A. J. \& CLEVELAND, D. W. 2012. Losing balance: the origin and impact of aneuploidy in cancer. EMBO Rep, 13, 501-14.

HU, D., MAYEDA, A., TREMBLEY, J. H., LAHTI, J. M. \& KIDD, V. J. 2003. CDK11 complexes promote pre-mRNA splicing. J Biol Chem, 278, 8623-9.

HU, D., VALENTINE, M., KIDD, V. J. \& LAHTI, J. M. 2007. CDK11(p58) is required for the maintenance of sister chromatid cohesion. J Cell Sci, 120, 2424-34.

KAWASHIMA, S. A., YAMAGISHI, Y., HONDA, T., ISHIGURO, K. \& WATANABE, Y. 2010. Phosphorylation of $\mathrm{H} 2 \mathrm{~A}$ by Bub1 prevents chromosomal instability through localizing shugoshin. Science, 327, 172-7.

KITAJIMA, T. S., HAUF, S., OHSUGI, M., YAMAMOTO, T. \& WATANABE, Y. 2005. Human Bub1 defines the persistent cohesion site along the mitotic chromosome by affecting Shugoshin localization. Curr Biol, 15, 353-9.

KITAJIMA, T. S., SAKUNO, T., ISHIGURO, K., IEMURA, S., NATSUME, T., KAWASHIMA, S. A. \& WATANABE, Y. 2006. Shugoshin collaborates with protein phosphatase 2A to protect cohesin. Nature, 441, 46-52.

KLEBIG, C., KORINTH, D. \& MERALDI, P. 2009. Bub1 regulates chromosome segregation in a kinetochore-independent manner. J Cell Biol, 185, 841-58.

MCGUINNESS, B. E., HIROTA, T., KUDO, N. R., PETERS, J. M. \& NASMYTH, K. 2005. Shugoshin prevents dissociation of cohesin from centromeres during mitosis in vertebrate cells. PLoS Biol, 3, e86.

NASMYTH, K. 2011. Cohesin: a catenase with separate entry and exit gates? Nat Cell Biol, 13, $1170-$ 7.

NISHIYAMA, T., LADURNER, R., SCHMITZ, J., KREIDL, E., SCHLEIFFER, A., BHASKARA, V., BANDO, M., SHIRAHIGE, K., HYMAN, A. A., MECHTLER, K. \& PETERS, J. M. 2010. Sororin mediates sister chromatid cohesion by antagonizing Wapl. Cell, 143, 737-49.

NISHIYAMA, T., SYKORA, M. M., HUIS IN 'T VELD, P. J., MECHTLER, K. \& PETERS, J. M. 2013. Aurora B and Cdk1 mediate Wapl activation and release of acetylated cohesin from chromosomes by phosphorylating Sororin. Proc Natl Acad Sci U S A, 110, 13404-9.

PERERA, D. \& TAYLOR, S. S. 2010. Sgo1 establishes the centromeric cohesion protection mechanism in G2 before subsequent Bub1-dependent recruitment in mitosis. $J$ Cell Sci, 123, 653-9. 
PETRETti, C., SAVOIAN, M., MONTEMBAUlt, E., GlOVER, D. M., PRIGENT, C. \& GIET, R. 2006. The PITSLRE/CDK11p58 protein kinase promotes centrosome maturation and bipolar spindle formation. EMBO Rep, 7, 418-24.

RIEDEL, C. G., KATIS, V. L., KATOU, Y., MORI, S., ITOH, T., HELMHART, W., GALOVA, M., PETRONCZKI, M., GREGAN, J., CETIN, B., MUDRAK, I., OGRIS, E., MECHTLER, K., PELlETIER, L., BUCHHOLZ, F., SHIRAHIGE, K. \& NASMYTH, K. 2006. Protein phosphatase 2A protects centromeric sister chromatid cohesion during meiosis I. Nature, 441, 53-61.

RIEDER, C. L. 2011. Mitosis in vertebrates: the G2/M and M/A transitions and their associated checkpoints. Chromosome Res, 19, 291-306.

SALIC, A., WATERS, J. C. \& MITCHISON, T. J. 2004. Vertebrate shugoshin links sister centromere cohesion and kinetochore microtubule stability in mitosis. Cell, 118, 567-78.

SCHMITZ, J., WATRIN, E., LENART, P., MECHTLER, K. \& PETERS, J. M. 2007. Sororin is required for stable binding of cohesin to chromatin and for sister chromatid cohesion in interphase. Curr Biol, 17, 630-6.

SONODA, E., MATSUSAKA, T., MORRISON, C., VAGNARELLI, P., HOSHI, O., USHIKI, T., NOJIMA, K., FUKAGAWA, T., WAIZENEGGER, I. C., PETERS, J. M., EARNSHAW, W. C. \& TAKEDA, S. 2001. Scc1/Rad21/Mcd1 is required for sister chromatid cohesion and kinetochore function in vertebrate cells. Dev Cell, 1, 759-70.

SUMARA, I., VORLAUfER, E., GIEFFERS, C., PETERS, B. H. \& PETERS, J. M. 2000. Characterization of vertebrate cohesin complexes and their regulation in prophase. $J$ Cell Biol, $151,749-62$.

TORRES, E. M., WILLIAMS, B. R. \& AMON, A. 2008. Aneuploidy: cells losing their balance. Genetics, 179, 737-46.

TREMBLEY, J. H., LOYER, P., HU, D., LI, T., GRENET, J., LAHTI, J. M. \& KIDD, V. J. 2004. Cyclin dependent kinase 11 in RNA transcription and splicing. Prog Nucleic Acid Res Mol Biol, 77, 263-88.

UHLMANN, F., LOTTSPEICH, F. \& NASMYTH, K. 1999. Sister-chromatid separation at anaphase onset is promoted by cleavage of the cohesin subunit Scc1. Nature, 400, 37-42.

WAIZENEGGER, I. C., HAUF, S., MEINKE, A. \& PETERS, J. M. 2000. Two distinct pathways remove mammalian cohesin from chromosome arms in prophase and from centromeres in anaphase. Cell, 103, 399-410. 
WANG, L. H., MAYER, B., STEMMANN, O. \& NIGG, E. A. 2010. Centromere DNA decatenation depends on cohesin removal and is required for mammalian cell division. $J$ Cell Sci, 123, 80613.

WATRIN, E., SCHLEIFFER, A., TANAKA, K., EISENHABER, F., NASMYTH, K. \& PETERS, J. M. 2006. Human Scc4 is required for cohesin binding to chromatin, sister-chromatid cohesion, and mitotic progression. Curr Biol, 16, 863-74.

WENDT, K. S., YOSHIDA, K., ITOH, T., BANDO, M., KOCH, B., SCHIRGHUBER, E., TSUTSUMI, S., NAGAE, G., ISHIHARA, K., MISHIRO, T., YAHATA, K., IMAMOTO, F., ABURATANI, H., NAKAO, M., IMAMOTO, N., MAESHIMA, K., SHIRAHIGE, K. \& PETERS, J. M. 2008. Cohesin mediates transcriptional insulation by CCCTC-binding factor. Nature, 451, 796-801. 